\title{
Morphosyntactic features and paradigmatic uniformity in two dialectal varieties of the island of Lesvos
}

\author{
Adamantios Gafos and Angela Ralli \\ New York University / Utrecht Institute of Linguistics, OTS, \\ University of Patras
}

This paper discusses data from the nominal paradigms of two dialectal varieties of East Lesvos, those of Thermi and Pamfila. It is shown that there is abundant evidence for the key role of the paradigm in the phonological realization of the [noun-clitic] clusters. We argue that the grammars of these dialectal varieties must crucially include constraints that require identity between related surface forms in the [noun-clitic] paradigm. This proposal has received considerable support by independent work, carried out mainly within Optimality Theory, in various languages. The Lesvian dialectal varieties, however, allow us to probe deeper into the precise statement of such intra-paradigmatic identity constraints. We show, first, that the identity constraints holding among various surface forms must have a limited domain of application, circumscribed by the forms of the paradigm and only those. Second, we show that intra-paradigmatic identity constraints do not require identity uniformly among all surface forms of the paradigm. Rather, distinct identity constraints hold between distinct forms. For instance, the identity constraint between the $\{+$ first person, + singular $\}$ and the $\{+$ third person, + singular $\}$ is different from that holding between the $\{+$ first person, + singular $\}$ and the $\{+$ first person, + plural $\}$. We argue, specifically, that the network of such intra-paradigmatic identity constraints is projected on the basis of shared morphosyntactic features along the dimensions of Person and Number that enter into the construction of the paradigm.

Keywords: Greek dialects, paradigm uniformity, morphosyntactic features 


\section{Introduction}

The language spoken on Lesvos belongs to the group of northern Greek dialects and displays the following two major phonological characteristics. First, the mid vowels, /o/ and /e/, become $[\mathrm{u}]$ and $[\mathrm{i}]$ respectively, when found in unstressed position. For example, standard Greek [ómorfo] 'nice' is pronounced as [ómurfu], and [éfere] '(he) brought' as [éfiri]. Second, the high vowels, /u/ and /i/, are generally deleted in unstressed position as in (1), except in cases where they carry contrasting morphological information, (2).

(1) Lesvian dialects

Standard Greek

a. [vnó], [vúnarus] 'mountain', 'big mountain' [vunó]

b. [pitnós], [pitínarus] 'rooster', 'big rooster' [petinós], [petínaros]

c. [pínu], [épna] 'I drink', 'I was drinking' [píno], [épina]

(2) Lesvian dialects
a. $\quad[$ kóv-u $],{ }^{*}[\mathrm{kóv}]$
'(I) cut'
b. [kóv]
'(he/she) cuts'
[kóv-o], vs.
[kóv-i]

Standard Greek

Considerable linguistic differences from village to village induce linguists (e.g. Kretschmer 1905, among others) to talk of dialectal varieties rather than of a single Lesvian dialect. In this paper, we deal with the paradigm of [noun-clitic] combinations in two such dialectal varieties of East Lesvos, those spoken in the villages of Thermi and Pamfila, henceforth dialect A and B respectively.

\section{The data}

The Lesvian [noun-clitic] paradigms in the two varieties under study show morpho-phonological differences with respect to the standard Greek correspondent, on the one hand, as well as from one variety to another, on the other. Let us consider the data in (3) where the noun [fílus] 'friend' is combined with the possessive postclitics. 'SG', 'PL' stand for Singular and Plural, respectively, and ' 1 ', '2,' ' 3 ' stand for first, second, and third person, respectively. We refer to the form [fílus] as the base of the [noun-clitic] paradigm. This is the form of the noun used to compute the phonological realization of the various [noun-clitic] outputs. We note that [fílus] is an independently occurring word, the masculine, nominative, singular form of the lexeme 'friend'. The ' $\sim$ ' in the third singular indicates variation between two forms, within the same speaker, one of the issues that is addressed in detail later in the paper. 
(3) Lesvian noun-clitic paradigm

\begin{tabular}{|c|c|c|c|}
\hline $1 \mathrm{sg}, /$ & $\begin{array}{l}\text { Dialect A } \\
\text { [fíluzim] }\end{array}$ & $\begin{array}{l}\text { Dialect B } \\
\text { [fílusim] }\end{array}$ & 'my friend' \\
\hline 2sG, /fílus-s/ & [fílus] & [fílus] & 'your friend' \\
\hline 3sG, /fílus-t/ & [fíluzit] [fílust] & [fílusit] [fílust] & 'his friend' \\
\hline 1PL, /fílus-mas/ & [fíluzmas] & [fílusmas] & 'our friend' \\
\hline 2PL, /fílus-sas/ & [fílusas] & [fílusas] & 'your friend' \\
\hline 3PL, /fílus-dun/ & [fíluzdun] & [fílustun] & 'their friend' \\
\hline
\end{tabular}

As a reference point, let us compare the data in (3) with the standard Greek data in (4).

(4) Standard Greek noun-clitic paradigm

$\begin{array}{ll}1 \mathrm{sG}, / \text { fílos-mu/ } & \text { [fílozmu] } \\ 2 \mathrm{sG}, / \text { fílos-su/ } & \text { [fílosu] } \\ 3 \mathrm{sG}, / \text { fílos-tu/ } & \text { [fílostu] } \\ 1 \mathrm{PL}, / \text { fílos-mas/ } & \text { [fílozmas] } \\ 2 \mathrm{PL}, / \text { fílos-sas/ } & \text { [fílosas] } \\ 3 \mathrm{PL}, / \text { fílos-tus/ } & \text { [fílostus] }\end{array}$

At first sight, certain differences between Lesvian and standard Greek seem to follow from independent phonological properties of the two languages. For instance, the /u/ in Lesvian [fílus] stands in place of /o/ in /fílos/ due to the midvowel raising in unstressed position. The / $\mathrm{u} /$ of the clitics $/ \mathrm{mu}, \mathrm{su}, \mathrm{tu} / \mathrm{does}$ not surface in Lesvian due to the dialectal law of high vowel deletion in unstressed position, hence, 3sg /fílus-tu/ surfaces as [fílust]. Also, the base-final /s/ of /fílus/ is deleted before another /s/, as in /fílus-su/ $\rightarrow$ [fílus] and /fílus-sas/ $\rightarrow$ [fílusas]. This is due to a process of /s/-deletion in /s-s/ clusters at the [hostclitic] boundary, apparently as way to avoid a violation of the well-known Obligatory Contour Principle (OCP, Leben 1973, McCarthy 1979, 1986), which states that 'Adjacent identical elements are prohibited'. As shown below, this deletion targets only $/ \mathrm{s} /$. Other coronals do not delete in the same context, see (5b), and in fact we observe a different response to the creation of $/ \mathrm{z}$-s/ clusters, namely, alternation of $/ z /$ with the palatal approximant $[j],(5 c) .{ }^{1}$

(5) Noun-clitic

a. /fílos-su/ 'your friend'

b. /kulán-su/ 'your tights'
Standard Greek

[fílosu]

*[fílossu]

[kulánsu]

*[kólasu $]$
Dialects A and B

[fílus]

*[fíluss]

[kuláns]

*[kúlas] 


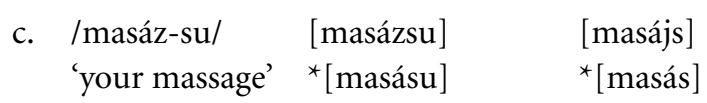

Though we do not undertake an analysis of the segmental processes related to the OCP in this paper, we note that /s/-deletion in Lesvian is a more restricted instance of the well-known law of first-coronal deletion in Greek. ${ }^{2}$ This is illustrated below with data from the formation of the perfective stem of verbs, ( $6 a, b, e, f, h, i)$, and deverbal nouns in $/-s i,-s i m o /,(6 c, d, g, j)$. In contrast to deletion at the [noun-clitic] boundary, this deletion affects any coronal in the first position of the /C-C/ cluster created at the morpheme boundary (Malikouti 1970).

(6) Standard Greek first-coronal deletion
a. /plá $\theta$-o/ [plá $\theta$ o] 'I mold'

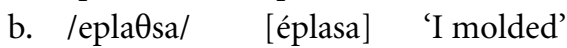
c. /plá $\theta$-si/ [plási] 'creation, world'
d. /plá $\theta$-simo/ [plásimo] 'molding'

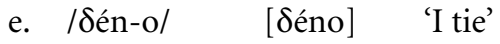

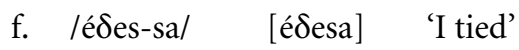

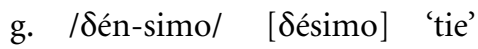
h. /skíz-o/ [skízo] 'I tear apart'
i. /éskiz-sa/ [éskisa] 'I teared apart'
j. /skíz-simo/ [skísimo] 'tearing apart'

Furthermore, because of regressive voicing assimilation, the word-final /s/ of /fílus/ becomes voiced [z] before the voiced / $\mathrm{m} /$, [fíluzmas], in the first person plural in standard Greek and in dialect A. This voicing is not applicable in dialect B. In that dialect, as can be observed in [fílusmas], there is no voicing assimilation in this cluster. However, voicing assimilation is observed in dialect $\mathrm{B}$ in the 3PL [fílustun], with progressive devoicing of the clitic's / $\mathrm{d} / \mathrm{after} / \mathrm{s} /$.

The third person plural clitic in both dialects is /-dun/, as opposed to /-tus/ in standard Greek. The existence of a voiced /d/ is shown by two facts. First, [dun] is the form of the clitic after vowel-final bases, as in (7). Second, there is no evidence for inter-vocalic voicing in these dialects, as shown by examples like [xálas-a] 'to cause (something) not to function-1sG-PAsT', [báf-a] 'fat woman', [Өálas-a] 'sea', and [bóx-a] 'unpleasant odor' (all nouns are given in their nominative, singular form; accent on [à] marks secondary stress).

(7) Dialects A and B [mána-dun] [xóra-dun]
Standard Greek

[mána-tus]

[xóra-tus] 


$$
\begin{array}{lll}
\text { [jítunà-dun] } & \text { 'neighbor-THEIR' } & \text { [jítonà-tus] } \\
\text { [kafé-dun] } & \text { 'coffee-THEIR' } & \text { [kafé-tus] }
\end{array}
$$

In this paper, we argue that the differences between the two dialectal varieties, as well as the deviations with respect to standard Greek, cannot be explained by phonological factors alone. Rather, these differences provide evidence for the crucial role played by certain mechanisms available to the morphology-phonology interface, namely the notion of the morphological paradigm itself and the notion of intra-paradigmatic identity relations. In what follows, we will examine these differences and the mechanisms that are needed to account for them.

\section{The /i/ epenthesis}

In (3), we have an /i/ between the final consonant of the noun and the initial consonant of the clitic in the $1 \mathrm{sg}$ and variably in the $3 \mathrm{sG}$, for both dialects. To understand the reasons behind the presence of this $/ \mathrm{i} /$, we begin by restricting our attention to the 1sG forms, [fíluzim] in dialect A and [fílusim] in dialect B. We argue that the presence of this /i/ is motivated by phonotactic constraints on what constitutes a well-formed final cluster in these dialects. Specifically, the final cluster that would be created by combining /fílus/ with the postclitic /m/ is not a possible word-final cluster. In Lesvian, final clusters consisting of obstruent-sonorant consonants are possible only if the sonorant is a coronal. See (8) (raised ' $y$ ' indicates palatalization). We encode this requirement with the constraint ${ }^{*}$ FinAL-CC ${ }^{[-\mathrm{Cor},+\mathrm{Son}]}$ in (9).

(8) Sonorant-final clusters in Lesvian
a. /xurév-un/ [xurévn] 'they dance-3PL-PREs'
b. /kúkl-u/ [kúkl] 'doll-MASC-GEN-SG'
c. /alévr-i/ [alévr] 'flour-NEUT-NOM-SG'
d. /mávr-i/ [mávr] 'black-FEM-NOM-sG'
e. /távli/ [távl $\left.{ }^{y}\right]$ 'backgammon'

(9) ${ }^{\star}$ FinAL-CC ${ }^{[-\mathrm{Cor},+ \text { Son }]}$

Word-final CC clusters where the second $\mathrm{C}$ is a non-coronal sonorant are not allowed.

We emphasize that this constraint is employed here as a cover name for the set of constraints that would underlie the inventory of permissible clusters in the dialects. We have yet to undertake a detailed study of the reasons that may be 
behind this restriction, but our observations are fully consistent with the need of such a constraint against non-coronal sonorants in the position of the second consonant of final CC clusters. The reason why the specification sonorant is part of this restriction is that, when the second consonant is an obstruent, all places of articulation are attested. Some examples of final coronals and their palatalized versions are [kléft] 'thief', [láps] 'shining' (standard Greek [lámpsi]), [ $\gamma$ ráfs] 'you write', $\left[t_{\gamma}\right.$ án $\left.^{y}\right]$ 'frying pan', [rixn ${ }^{y}$ ] 'he throws', and [kakúrj] 'criminals'; examples of final labials include [lásp] 'mud', [ákarp] 'fruitless'; and examples of final velars include [saly agukáfk ${ }^{\mathrm{y}}$ ] 'snail's cell', [kal ${ }^{\mathrm{y}}$ 'máfk $^{\mathrm{y}}$ ] 'Orthodox priest's head gear'.

Another plausible interpretation of the /i/ in [im] of the 1sG is that it results from a Turkish influence. In Turkish, a language that was in contact with Lesvian for more than four centuries, a similar form, consisting of /High Vowel $+\mathrm{m} /$, is found in the first person possessive clitic when the preceding noun ends with a consonant. Compare (10) and (11) below. The independent fact of vowel harmony in Turkish accounts for the assimilation of the suffixal/i/ to the features [round] and [back] of the stem vowel.

(10) Turkish
a. /arkadas-im/ [arkadasim] 'my friend'
b. /ev-im/ [evím] 'my house'
c. /okul-im/ [okulúm] 'my school'
d. /göz-im/ [gözüm] 'my eye'

(11) Lesvian (Dialect B)
a. /fílus-mu/
[fílusim]
'my friend-MASC-NOM-SG'
b. / yátas-mu/
[үátasim]
'my cat-FEM-GEN-SG'

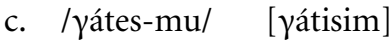
'my cats-FEM-NOM-PL' vs.
d. /fílo-mu/ [fílum] 'my friend-MASC-GEN-SG'

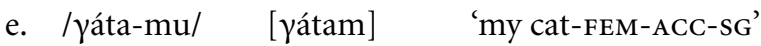

Although the Turkish contribution to the development of an /-im/ postclitic form should not be underestimated, there is additional independent evidence for /i/ epenthesis in the dialects. ${ }^{3}$ An epenthetic /i/ is generally employed in contexts other than the $/ \mathrm{sm} /$ word-final cluster in [noun-clitic] combinations. Thus, in (12a), /i/ epenthesis applies at the word-final context to avoid the /zm/ cluster that would result after the deletion of the /u/ in /kózmu/. In (12b,c,d), /i/ epenthesis applies in the word-initial context when various consonant-final pronouns and particles are combined with consonant-initial words. Note that 
our goal here is not to identify the precise reasons behind /i/ epenthesis in all the contexts where it is found. Rather, our goal is to provide evidence that /i/ is the default vowel supplied to break-up consonant clusters, independent of whether this is due to constraints on syllabification or due to constraints on footing and higher prosody (see Drachman and Malikouti-Drachman 1999 for a review of Greek prosody).

(12) Lesvian (dialects A, B)

a. [t kóz-i-m ta lója] 'the words of the world'

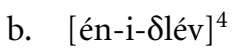
'(he/she) does not work'

c. [tun-i-psáxn $\left.{ }^{y}\right]$ '(he/she) looks for him'

d. [mín-i-majirévs psárja] '(are you) cooking fish?'
Standard Greek

[tu kózmu ta lója]

of-the-world the words

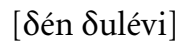

NOT-works(he/she)

[ton psáxni]

HIM-looks

[mípos majirévis psárja]

Can it be $\operatorname{cook}(\mathrm{you})$ fish-PL?

Focusing on $/ \mathrm{sm} /$ or $/ \mathrm{zm} /$ clusters, in particular, our claim is that /i/ appears to avoid the creation of such final clusters when these would result either from an underlying /s-m/, where '-' indicates a morpheme/word boundary, or from deletion of a high vowel at the end of word, as in /kózmu/ $\rightarrow$ [kózim]. The qualification 'final' is crucial. The same clusters are perfectly legitimate in other contexts in Lesvian and standard Greek. As shown in (13), /zm/ or / sm/ clusters are attested in word-initial and word-medial position, after the deletion of an unstressed high vowel. No /i/ is necessary here because, in the prevocalic context, /sm, zm/ are well-formed onsets in Greek and these dialects.

(13) Standard Greek

a. [simerinós]

b. [asiménjos]

c. [simáoi]

d. [zmínos]

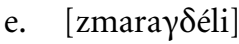

f. [zmaríßa]

g. [asimóno]
Lesvian (A and B)

\begin{tabular}{|c|c|}
\hline of today' & [smirnós] \\
\hline 'made of silver' & [asménjus] \\
\hline 'point' & [smá $\delta$ ] \\
\hline 'flock' & [zmínus] \\
\hline proper name' & {$\left[\right.$ zmara $\left.\delta \delta e ́ l{ }^{y}\right]$} \\
\hline ind of f f ch, & [zmarí́a] \\
\hline ake into silve & [asmónu] \\
\hline
\end{tabular}

Finally, we note that in stating our observation that $/ \mathrm{sm}, \mathrm{zm} /$ are not possible clusters word-finally, the notion of word is taken in a broad sense, referring not only to one-word units, but also to clusters of words and phrasal affixes, if we assume that clitics are considered to belong to a closed set of phrasal affixes, following Anderson (1992). ${ }^{5}$ 
To conclude, in Lesvos we find an epenthetic vowel [i] in the [noun-clitic] environment and also in the [particle or proclitic-verb] context. ${ }^{6}$ The other instances of /i/ in the data in (3), specifically in the 3s forms of the [nounclitic] paradigms, are related to the facts of voicing assimilation. Thus, before we provide an account of the presence of /i/ in those contexts, we must turn to review the facts of voicing assimilation.

\section{The /s/ voicing}

In dialect $A$, the final consonant of the base /fílus/ is the target of voicing assimilation applying at the morpheme and word-clitic boundary, as shown by the 1PL [filuzmas] or the 3PL [filuzdun], and further illustrated by the examples in $(14 a, b, c)$.
a. /ksexas-ménos/
[ksixazménus]
'forget-PPART'
'forgotten'
b. /jítonas-mas/
[jítunàzmas]
'neighbour-OUR'
'our neighbour'
c. /mas-bóljase/
[mazbóljasi]
'US-(s/he)-vaccinated'
'(s/he) vaccinated us'
vs.
d. /asiménjos/
[asménjus], * [azménjus]
'silver-ADJ-MASC'
'silver'
e. /prasiná $\delta$ a/

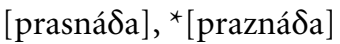
'green-NOM-FEM'
'greenery'
f. /énas mílos/
[énas mílus], * [énaz mílus]
'one mill'

Interestingly, the 1sG [fíluzim] also shows a voiced /z/, even though the target of voicing $/ \mathrm{z} /$ is not adjacent to the potential trigger of voicing assimilation, $/ \mathrm{m} /$. More surprisingly, the first variant of dialect A's 3sg [fíluzit] ( [fílust]) also shows a voiced $/ \mathrm{z} /$, even though there no voiced consonant in the vicinity of this segment that could act as a source of this voicing.

In fact, it is easy to see how the 1sg [fíluzim] could be accounted for in a rule-based theory (Chomsky \& Halle 1968, Kenstowicz 1994). If we posit that the rule of voicing assimilation applies before /i/ epenthesis, then given the $1 \mathrm{sG}$ input /fílus-m/, /s/ would be in the environment of voicing assimilation just as it is in the case of the 1PL [fíluzmas]. After voicing assimilation applies, the 
intermediate form would be [fíluzm]. Then, via epenthesis, motivated by the familiar phonotactic constraint on word-final clusters, the final outcome [fíluzim] is derived.

A rule-ordering analysis in precisely these terms is proposed by Newton (1972) to account for the voicing in [fíluzim] and also for its variant [fílusim], which are both attested in Lesvos. ${ }^{7}$ We illustrate Newton's analysis in (15) with the forms [ $\theta$ kózim] [ $\theta$ kósim] (Newton 1972:208). The rule ordering appropriate for $[\theta$ kózim] is in (15a). This output is achieved when epenthesis is ordered after voicing assimilation of $/ \mathrm{s} /$ to $[\mathrm{z}]$ before $/ \mathrm{m} /$. In (15b), instead, ordering epenthesis before voicing assimilation will produce the other output [ $\theta$ kósim].

(15) Rule ordering account of [ $\theta$ kózim] [ $\theta$ kósim] 'my own'

a. Underlying form

High Vowel Loss

Fricative devoicing

Voice Assimilation

Epenthesis

b. Underlying form

High Vowel Loss

Fricative devoicing

Epenthesis

Voice Assimilation
/Sikós-mu/

¿kósm

Өkósm

Өkózm

Өkózim

Output: [Өkózim]

/ Sikós-mu/

¿kósm

Өkósm

Өkósim

Output: [ $\theta$ kósim]

However, the rule ordering solution fails when one considers the $3 \mathrm{sg}$ form [fíluzit] with a voiced $/ \mathrm{z} /$ in dialect $\mathrm{A}$. The voicing of the $/ \mathrm{z} /$ here cannot be explained by rule ordering. In the morphosyntactic context of $3 \mathrm{sG}$, the final /s/ of base /fílus/ is not in the environment of the voicing assimilation at any stage of the derivation and for any rule ordering (since $/ t /$ is voiceless). This shows that other forces are at work here. ${ }^{8}$ In particular, observe that in the 3PL [fíluzdun] the final /s/ of the noun /filus/ is voiced due to the independent fact of voicing assimilation described earlier. We argue that the voiced /s/ in the 3sG [fíluzit] is present because of a requirement that all occurrences of the noun within the [noun-clitic] paradigm must be identical. In other words, voicing assimilation is responsible for the voiced $/ z /$ in the $3 \mathrm{PL}$ [fíluzdun]. This voiced $/ z /$, in turn, is extended to or induces the voicing seen in the 3sg [fíluzit], even though voicing assimilation is not applicable in this latter morphosyntactic context. A schematic representation of this extension is shown in (16). 
(16) Extension of voicing to the 3sg

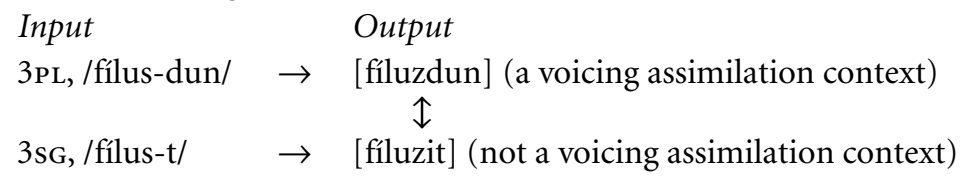

There are two apparent counterexamples that seem to cast doubt on our proposal. First, there is a voiceless /s/ in the 2sG and 2PL forms [fílus] and [fílusas]. This /s/, however, is not the final consonant of the noun /fílus/, but rather the first consonant of the corresponding clitics, i.e., /s/ and /sas/. The second apparent complication is that, in fact, the $3 \mathrm{sg}$ shows variation between [fíluzit] and [fílust], where the second variant shows a voiceless /s/. Crucially, we only find such variation for the 3sg. The 1sg is always [fíluzim], never *[fíluzm] or *[fílusim]. This fact implies that the identity requirement introduced in the preceding paragraph fails to show its effects within particular persons. Rather than being a problem for our proposal, we argue that the variation in the $3 \mathrm{sg}$ constitutes an argument for it and, furthemore, that it calls for certain refinements in the grammatical statement of intra-paradigmatic identity constraints.

\section{Theoretical assumptions}

The theoretical model of grammar we assume in this paper is that of Optimality Theory (Prince \& Smolensky 1993, McCarthy \& Prince 1993). In Optimality Theory (henceforth, OT), Universal Grammar consists of a set of well-formedness conditions or constraints. The output of phonology is not constructed by a step-by-step application of rules. Instead, given an input form, the grammar first generates a set of candidate outputs. Each of the candidates in this set is then evaluated by the constraints. The output of the grammar is the candidate that best satisfies the constraints, called the optimal candidate. The set of constraints (CON), the function that generates all candidates (GEN), and the evaluation procedure (EVAL) are all assumed to be fixed parts of the architecture of Universal Grammar. Grammars of particular languages are constructed by imposing a ranking among the constraints in the universal constraint set CON. We illustrate the model with explicit examples below.

Within OT, we especially rely on the notion of correspondence relation as developed in the work by McCarthy \& Prince (1995). In its most general sense, a correspondence relation is a relation between two linguistic forms that imposes 
identity constraints among elements of these forms. For instance, a lexical input and its output form enter into a correspondence relation. A correspondence relation comes with a set of constraints, known as correspondence constraints. These constraints require identity between two related forms across different dimensions, which are considered to be linguistically significant.

We illustrate these remarks with three basic correspondence constraints in (17) below. Max requires that all segments in the input be present in the output, and Dep requires that the output does not include segments not present in the input. The constraint $\operatorname{IDENT}(\mathrm{F})$ is concerned with identity in terms of featural properties.

(17) Some basic constraints of correspondence theory

a. Max

Every segment of the Input has a correspondent in the Output (bans deletion).

b. DEP

Every segment of the Output has a correspondent in the Input (bans epenthesis).

c. $\operatorname{IdENT}(\mathrm{F})$

An Input segment and its correspondent in the Output must have identical values for feature $\mathrm{F}$ (bans featural changes).

Intuitively, correspondence constraints penalize disparity between inputs and outputs. MAx does this by banning segmental deletion and Dep by banning segmental epenthesis. IDENT(F) penalizes disparity by banning featural mismatches between input and output correspondents. Epenthesis, deletion, and featural change are all different ways of breaching the identity between an input and an output form. In principle, there is a correspondence constraint requiring identity between input and output for each linguistically significant dimension of phonological form (e.g., not only segments and their features but also prosodic properties such as location of stress or suprasegmental properties such as tone; see McCarthy 2000a for relevant discussion).

\section{Basic constraint interactions}

We now turn to see how these constraints interact to determine the realization of the various [noun-clitic] combinations in our data.

We begin with dialect $A$, whose [noun-clitic] paradigm consists of the forms [fíluzim, fílus, fíluzit fílust, fíluzmas, fílusas, fíluzdun]. Consider, first, 
the 3PL [fíluzdun]. The input to the formation of the 3PL consists of the paradigm's base, the form /fílus/, and the clitic/dun/. There is therefore a violation of BO-IDENT (Voice), because the /s/ of the base surfaces as $[z]$ in the 3PL output [fíluzdun]. 'B' in the prefix of the identity constraint BO-IDENT stands for Base and ' $\mathrm{O}$ ' stands for Output, the pair of forms over which identity is required. This change in the voicing specification between base /s/ and its output in /fílus-dun/ $\rightarrow$ [fíluzdun] is related to a property of consonant clusters in word-phrasal affix combinations. Any consonant cluster at the juncture between a word and a phrasal affix must be homogenous with respect to voice. We ascribe this fact to the presence of the constraint VoiceAgree in the grammar, (18). It is conceivable that this constraint can be stated in its most general form, that is, without specifying the morphological domain of its application. However, since we have not studied the details of voicing assimilation in the two dialects, we opt for the most conservative statement consistent with our data, by also specifying the domain of application (see Fromkin 2000 on voicing assimilation in English).

\section{VoiceAgree}

In a CC cluster, at the word-phrasal affix juncture, the consonants must agree in voice.

For input /fíluz-dun/, then, we have two competing requirements: VoICEAgreE requires that the output be [fíluzdun], but BO-IDENT requires that the output be [fílusdun]. Such situations of conficting demands on the realization of linguistic form are prototypical in OT. Constraint conflict is resolved by imposing a prioritization of the relevant constraints. The fact that dialect A opts for the form [filuzdun] is expressed by saying that the constraint VoiceAgree is ranked higher than the constraint BO-IDENT. Graphically, the situation is represented by a tableau, shown in (19) below. The input is shown in the upper left corner. The constraints are shown in the top row. The two competing outputs, the candidates, occupy the second and third rows. The actual output is indicated by and constraint violations are shown by ${ }^{(*)}$ in the column of the constraint which is violated ('! marks a fatal violation, given the ranking of the constraints). 
(19) Voicing in the 3PL: VoICEAgree $>>$ BO-IDENT

\begin{tabular}{|l||c|c|}
\hline$/$ /fílus-dun/ & VoiceAgree & BO-Ident \\
\hline \hline a. fílusdun & $* !$ & \\
\hline b. fíluzdun & & $*$ \\
\hline
\end{tabular}

This tableau compares the performance of the actual output [fíluzdun] to one of the many possible realizations of /fílus-dun/. Considering other failed realizations provides more information about the ranking of the constraints. For example, we may consider a candidate with devoicing of the first consonant of the clitic, as in dialect B's actual output [filustun], rather than with voicing the final consonant of /fílus/. This candidate satisfies VoICEAgreE, but it incurs a violation of IDENT ${ }^{\mathrm{CL}}$, the constraint that disallows featural disparities for the clitic between its input and its output, stated in (20).

(20) IDENT $^{\mathrm{CL}}$

An input segment and its correspondent in the output must have identical values for feature $\mathrm{F}$.

The failure of candidate [fílustun] in dialect A, thus, shows that we must add to the grammar of that dialect the ranking IDENT ${ }^{\mathrm{CL}}>>$ BO-IDENT. Tableau (21) summarizes the ranking relations inferred so far. The dotted line between IDENT $^{\mathrm{CL}}$ and VoICEAgreE indicates that the ranking between these two constraints is irrelevant. That is, whether the ranking is IDENT ${ }^{\mathrm{CL}}>>$ VoICEAgree or VoiceAgree $>>$ Ident $^{\mathrm{CL}}$, the resulting surface form does not change.

(21) 3PL [fíluzdun]: IdENT ${ }^{\mathrm{CL}}$, VOICEAgREe $>>$ BO-IdENT

\begin{tabular}{|l||c:c|c|}
\hline$/$ fílus-dun/ & IDENT $^{\text {CL }}$ & VoICEAGREE & BO-IDENT \\
\hline \hline a. fílustun & $\star !$ & & \\
\hline b. fílusdun & & $\star !$ & \\
\hline c. fíluzdun & & & $*$ \\
\hline
\end{tabular}

Furthermore, the fact that the inhomogeneity in voicing of the /s-d/ cluster in /fílus-dun/ is repaired by changing the voicing specification of a segment rather than by deletion or epenthesis of a segment implies that the MAX, DeP constraints are also ranked higher than BO-IDENT. This is illustrated formally in tableau (22). 
(22) 3PL [fíluzdun]: MAX, DeP >> BO-IDENT

\begin{tabular}{|l||c|c|c|}
\hline /fílu-dun/ & MAx & DeP & BO-IDENT \\
\hline \hline a. fíludun & $\star !$ & & \\
\hline b. fílusidun & & $* !$ & \\
\hline c. fíluzdun & & & $\star$ \\
\hline
\end{tabular}

The grammar, as constructed so far, also accounts for the 1PL form [fíluzmas] from /fílus-mas/. The ranking VoiceAgree $>>$ BO-IDENT dictates voicing of the final /s/ of the input /fílus/ before the voiced /m/ of the clitic /mas/. ${ }^{9}$

Consider now the 1sG. The input is /fílus-m/ and the output is [fíluzim] in dialect A. In Section 3, we have argued that in the dialects under study, final CC clusters where the second $\mathrm{C}$ is a non-coronal sonorant are not allowed; we have encoded this requirement with the constraint $\mathrm{CoR}_{-} \mathrm{SoN}^{2 \mathrm{nd}}$, repeated in (23) below.

\section{(23) Cor-Son $^{2 \text { nd }}$}

Word-final CC clusters where the second C is a non-coronal sonorant are not allowed.

Thus, for input /fílus-m/, we have another instance of constraint conflict. The two conflicting constraints are shown in tableau (24). Candidate (24a) contains the illicit word-final /sm/ cluster, hence the violation of Cor-Son ${ }^{2 n d}$. Candidate (24b), the actual output, employs epenthesis, hence the violation of DEP. In the grammar of dialect A, then, we must state that Cor-Son ${ }^{2 n d}>>$ DeP. The fact that $/ \mathrm{s} /$ is voiced in [fíluzim] is taken up in the next section.

(24) Epenthesis in 1sG: CoR-SoN ${ }^{2 n d}>>$ DeP

\begin{tabular}{|l||c|c|}
\hline$/$ fílus-m/ & COR-SON $^{2 \text { nd }}$ & DEP \\
\hline \hline a. fílusm & $\star !$ & \\
\hline b. fíluzim & & $*$ \\
\hline
\end{tabular}

Intuitively, the tableau above shows that illicit word-final clusters are avoided by epenthesis. One can imagine other ways that may be employed to resolve such clusters. For instance, one such way is deletion of one of the consonants in the offending cluster. This is shown in (25), where the actual output in (25c) is compared to $(25 \mathrm{a}, \mathrm{b})$, two forms in which one of the consonants of the illicit 
cluster has been deleted. Deletion causes a violation of MAx. Since (25c) is the actual output, we may infer that MAx is ranked higher than DeP.

(25) Not deletion, but epenthesis in the 1SG: MAX $>>$ DeP

\begin{tabular}{|l||c|c|}
\hline$/$ /fílus-m/ & MAX & DeP \\
\hline \hline a. fílum & $* !$ & \\
\hline b. fílus & $* !$ & \\
\hline c. fíluzim & & $*$ \\
\hline
\end{tabular}

In (26), we summarize the ranking relations that must be part of dialect A's grammar, as they have been inferred so far.

$$
\begin{aligned}
& \text { Grammar for dialect A } \\
& \text { IDENT }^{\text {CL }} \text {, VoICEAGREE }>>\text { BO-IDENT } \\
& \text { MAX, CoR-Son }{ }^{2 \text { nd }}>>\text { DEP }>>\text { BO-IDENT }
\end{aligned}
$$

\section{Paradigm uniformity}

In this section, we take up the issue of voicing in the 1sG [fíluzim] of dialect A. In Section 4, we argued that the presence of the voiced /z/ in [filuzim] cannot be derived within a derivational conception of phonology. Rather, the presence of this voicing requires reference to a constraint that demands identity among the realizations of the base /fílus/ across its various contexts of occurrence, as stated in (27). In past literature, constraints applying between different surface forms of a morpheme's paradigm are usually studied under the name of analogy (Anttila 1977). In generative grammar, the study of the effects of such constraints and the concept of paradigm uniformity is introduced by Kiparsky $(1978,1995) .{ }^{10}$ More recently, the study of paradigm uniformity has resurfaced in work within Optimality Theory (see, among others, Benua 1995, Burzio 1993, 1994, 1998, Kraska-Szlenk 1995, Buckley 1999, Kenstowicz 1997, McCarthy 2000b, Steriade, to appear). Constraints requiring uniformity or identity between related output forms are also called Output-Output $(\mathrm{OO})$ faithfulness constraints or simply OO identity constraints. The statement of the contraint in (27) follows the definition in Kenstowicz (1997) and Steriade (to appear). 


\section{(27)}

\section{UNIFORMITY}

A lexical item has the same realization for feature $F$ in its various contexts of occurrence.

Let us illustrate the leveling effects of UNIFormity with the 1sg [fíluzim]. As we have seen, combining the base /fílus/ with some of the clitics results in phonological action. For instance, in the 1PL /fílus-mas/, voicing assimilation of /s/ before $/ \mathrm{m} /$ gives [fíluzmas]. The effect of UNIFORMITY is to extend this voicing to morphosyntactic contexts where the trigger of that phonological action (of voicing) is not present. The 1sG [fíluzim] is an example of such a context. In [fíluzim], the base-final consonant $/ \mathrm{z} /$ is not adjacent to the trigger of the voicing assimilation. Yet, that consonant is voiced. ${ }^{11}$ Formally, this levelling effect is expressed in tableau (28) below. Candidate (28a) in this tableau maintains the voiceless /s/ of the base but violates UNIFORMITY, since in the 1PL the base surfaces with a /z/, [fíluzmas]. The actual output [fíluzim], in (28b), incurs a violation of BO-IDENT. We thus infer that UNIFORMITY $>>$ BO-IDENT.

(28) Extension of voicing to the 1sG: Uniformity >> BO-Ident

\begin{tabular}{|l||c|c|}
\hline$/$ /fílus-m/ & Uniformity & BO-IDENT \\
\hline \hline a. fílusim & $\star !$ & \\
\hline b. fíluzim & & $\star$ \\
\hline
\end{tabular}

UNIfORMity's levelling effect is directional in the sense that it is the voicing in the 1PL that is transfered to the voicing in the 1sG. This is a consequence of the fact that both VoiceAgree and UNiformity are ranked higher than BO-IDENT, namely, VoiceAgree, Uniformity >> BO-Ident. To see this, consider in (29) the performance of various alternative realizations of the $1 \mathrm{sG}$ and $1 \mathrm{PL}$ in parallel (henceforth, in tableaux we write VA for VoiceAgree, Unif for Uniformity, BO-I for BO-IDENT, and $\mathrm{I}^{\mathrm{CL}}$ for IDENT ${ }^{\mathrm{CL}}$ ). Candidate (29a) illustrates the case where uniformity of voicing is satisfied by maintaining the voiceless /s/ throughout the 1sG, 1PL. In this set of surface forms, it is the voiceless $/ \mathrm{s} /$ of the $1 \mathrm{sg}$ that is extended to the 1PL. However, this violates VoiceAgree, a constraint which is undominated in dialect A. If, as in candidate (29b), the 1PL is realized with voicing but the 1sG maintains the voicelessness of its base /filus/, then VoiceAgree is satisfied but a nonuniform paradigm results. Given the ranking of the constraints, the optimal realization of the two forms must satisfy both VoiceAgree and Uniformity by levelling to a voiced / $\mathrm{z} /$, at the expense of the lower-ranked BO-IDENT. ${ }^{12}$ 
(29) Directionality of levelling (from 1PL to 1SG)

\begin{tabular}{|ll||c:c|c|}
\hline \multicolumn{2}{|l||}{ /fílus-m/ } & VA & UNIF & BO-I \\
\hline \hline a. & $\begin{array}{l}\text { fílusim } \\
\text { fílusmas }\end{array}$ & $* !$ & & \\
\hline b. & $\begin{array}{l}\text { fílusim } \\
\text { fíluzmas }\end{array}$ & & $* !$ & \\
\hline c. & $\begin{array}{l}\text { fíluzim } \\
\text { fíluzmas }\end{array}$ & & & $* *$ \\
\hline
\end{tabular}

This tableau shows that Uniformity's levelling effects are not automatic, but they are present only under the particular ranking shown above. Specifically, on the one hand, the ranking VoICEAgree $>>$ BO-IDENT enables phonological action, that is, voicing assimilation of the final $/ \mathrm{s} /$ in the context before a voiced clitic-initial consonant. On the other hand, the ranking UnIformity >> BO-IDENT enforces the transfer of voicing to other contexts within the paradigm where voicing assimilation would otherwise not apply. Thus, if Uniformity was ranked below BO-IDENT, then the 1sG would be [filusim]. This point becomes important when we deal with the variation in the $3 \mathrm{sg}$ [fíluzit] [fílust]. The second variant indicates that OO-identity forces like that of UnIformity can be suppressed within specific morphosyntactic contexts, here the $3 \mathrm{sg}$.

Before proceeding, let us consider the term various contexts of occurrence in the statement of UNIFORMity, in (27). It is important to stress that the forms over which UNIFORMiTy applies must be limited to the occurrences of the noun with the clitic set of forms. To see this, we must first recall that the noun [fílus] 'friend' is an independently occurring word, the masculine, nominative, singular form of the lexeme 'friend'. Uniformity cannot require identity between the independently occurring noun [fílus] outside of the [noun-clitic] paradigm and its form [fíluz] within the [noun-clitic] paradigm. If it did, all instances of the noun, including those outside the [noun-clitic] set of forms, would level to [fíluz] or [fílus], and this is not what we find. We may thus infer a basic grammatical requirement for the application of UNIFORMITY, or any OO-identity constraint for that matter, namely, the notion of domain of application. UNIFORMiTy must be specified to apply only within the set of forms of a specific paradigm. In our case, the set of [noun-clitic] forms comprises a paradigm defined on the morphosyntactic categories of Person, with values 
from the set $\{1,2,3\}$, and Number, with values from the set \{Singular, Plural\}. A (morphosyntactic) context is any pair of Person, Number features (i.e., 1sG, $2 \mathrm{sG}, 3 \mathrm{SG}, 1 \mathrm{PL}, 2 \mathrm{PL}, 3 \mathrm{PL}$ ). These are the contexts comprising the domain of application of UnIFORMiTy.

We turn now to the $3 \mathrm{sg}$ of dialect A. The input to the formation of the $3 \mathrm{sg}$ is /fílus-t/. The output shows variation between [fíluzit] and [fílust] within the same speaker. In this section, we focus on the form [fíluzit]. We will take up the equally important issue of variation in the next section. At first, the presence of epenthesis in [fíluzit] may be surprising. In the 1sG [fíluzim], epenthesis is motivated as a repair for the non-permissible final cluster in /fílus-m/. The same motivation is not available for the /i/ in the 3sG, however, since final /st/ clusters are well-attested in both underived, $(30 \mathrm{a}, \mathrm{b})$, and derived environments, (30c, d).

(30) Final /st/ clusters in both dialects
a. [píst]
'faith'
b. [anést]
'(proper name)'
c. [xtíst]
'builder' (from /xtís-ti/ 'build-ER-ACC-sG')
d. [anaynóst]
'reader' (from /anaүnós-ti/'read-ER-ACC-SG')

We now argue that the presence of this /i/ in the 3sg [fíluzit] is another, this time more indirect, effect of UNIFORMITY in the grammar. Recall that UNIFORMITY requires that the final /s/ in the output of the combination /fílus-t/ be voiced, due to UnIFormity >> BO-IDENT inferred earlier. This effectively favors the output [fíluzt] shown in candidate (31a) below (UNIFOrMITY is not shown in this tableau). However, [fíluzt] would violate VoiceAgree because of the inhomogeneous voicing in /zt/. Voicing the consonant of the clitic to give [fíluzd], (31b), incurs a violation of IDENT ${ }^{\mathrm{CL}}$, the constraint that disallows featural disparities for the clitic between its input and its output (that the input form of the $3 \mathrm{sg}$ clitic is / $\mathrm{t} /$ can be seen from examples like /mana-tu/ 'his mother' $\rightarrow$ [manat]). Deleting one of the consonants, as in (31c), is also not an option because of the violation of Max that this would incur. As we have inferred earlier, MAX $>>$ DeP. Hence, epenthesis, as in candidate (31d), is correctly predicted by our grammar as the option for resolving the offending /z-t/ cluster. ${ }^{13}$ 
(31) Epenthesis in 3sG, [fíluzit]

\begin{tabular}{|c|c|c|c|c|}
\hline /fílus-t/ & VA & $\mathrm{I}^{\mathrm{CL}}$ & Max & DEP \\
\hline a. fíluzt & $* !$ & & & \\
\hline b. fíluzd & & $* !$ & & \\
\hline c. fílut & & & *! & \\
\hline d. fíluzit & & & & * \\
\hline
\end{tabular}

The second person forms of dialect A are 2sG [fílus] from /fílus-s/, and 2PL [fílusas] from /fílus-sas/. The absence of voicing in these forms is due the /s/deletion before the /s/-initial clitics, discussed in Section 2. Deletion of the basefinal /s/ precludes leveling of voicing to these forms, since the deleted /s/ is by definition not part of the output form of the base. The only forms where levelling could occur and does occur are the 1sg /fílus-m/ $\rightarrow$ [fíluzim] and 3sG /fílus-t/ $\rightarrow$ [fíluzit] discussed above.

In (32), we summarize the grammar for dialect $A$. As a consequence of the bottom-ranked status of BO-IDENT in this grammar, the voicing assimilation enforced by VoiceAgreE affects the final consonant of the base, e.g., 3PL /fílus$\mathrm{dun} / \rightarrow$ [fíluzdun], 1PL/fílus-mas/ $\rightarrow$ [fíluzmas]. This voicing is transferred to other morphosyntactic contexts such as the $1 \mathrm{sg}$ [fíluzim] or the 3sg [fíluzit] due to the high-ranked status of Uniformity. We will take up the issue of variation in the 3sg [fíluzit] [fílust] in the next section.

$$
\begin{aligned}
& \text { Grammar for dialect A } \\
& \text { VoiceAgree, Uniformity }>>\text { BO-Ident } \\
& \text { Ident }^{\text {CL }} \text {, VoiceAgree, Max, Cor-Son }{ }^{2 \text { nd }}>>\text { Dep }>>\text { BO-Ident }
\end{aligned}
$$

Let us now turn to dialect B's [noun-clitic] paradigm, which consists of the forms [fílusim, fílus, fílusit fílust, fílusmas, fílusas, fílustun]. In contrast to dialect A, dialect B's base /fílus/ is realized consistently as [fílus] throughout the relevant surface forms. This fact about dialect B cannot be a consequence of Uniformity alone. Compare B’s forms [fílusim, fílusit fílust, fílusmas, fílustun] to another set [fíluzim, fíluzit, fíluzmas, fíluzdun], which is almost identical to that of dialect A (almost, since we have put aside the issue of variation, for the moment). Both of these sets satisfy Uniformity. Thus, the reasons behind the choice of the first set must be sought in the ranking relations among the rest of the constraints in the grammar of dialect B. Most informative, in this respect, is dialect B's choice in resolving the inhomogeneous voicing 
specification at the base-clitic boundary in the 3PL /fílus-dun/ $\rightarrow$ [fílustun]. The $3 \mathrm{PL}$ clitic of dialect B is underlyingly/-dun/, since this is the form surfacing after vowel-final nouns, e.g., [manadun] 'their mother'. Thus, dialect B opts for progressive devoicing of the clitic's /d/, [fílustun], rather than regressive voicing of the final /s/ as in dialect A's [fíluzdun]. Tableau (33) illustrates the ranking for this devoicing of the clitic in dialect B. Candidate (33a) [fílusdun] maintains the voicing specifications of the input, thereby incurring a violation of VOICEAgree. Candidate (33b) resolves the differing voicing specifications by voicing of the noun-final $/ \mathrm{s}$ /, which incurs a violation of BO-IDENT. The actual output in (33c), instead, opts for devoicing of the clitic consonant. We can thus infer that VoiceAgree, BO-IDENT $>>$ Ident $^{\mathrm{CL}}$.

Dialect B, 3PL /fílus-dun/: VoiceAgree, BO-IDENT $>>$ IDENT $^{\mathrm{CL}}$

\begin{tabular}{|l||c:c|c|}
\hline /fílus-dun/ & VA & BO-I & I $^{\mathrm{CL}}$ \\
\hline a. fílusdun & ${ }^{*}$ & & \\
\hline b. fíluzdun & & ${ }^{\star} !$ & \\
\hline c. fílustun & & & $\star$ \\
\hline
\end{tabular}

This ranking can be compared to that of dialect A: VoICEAgree, IDENT ${ }^{\mathrm{CL}}>>$ BO-IDEnt. As shown by the top-ranked status of VoiceAgree, both dialects enforce homogenous voicing in /s-C/ clusters, but they employ different means to this end. This difference between the two dialects is formally expressed by exchanging the place of BO-IDENT and IDENT ${ }^{\mathrm{CL}}$ in their respective constraint hierarchies.

The existence of 1PL [fílusmas] in dialect B, however, indicates that under certain conditions the requirement of VoICEAgree can be suspended. In the $1 \mathrm{PL} /$ fílus-mas/ $\rightarrow$ [fílusmas], given the low-ranked status of IDENT ${ }^{\mathrm{CL}}$, we expect devoicing of the clitic-initial $/ \mathrm{m} /$ so as to satisfy the demands of VoiceAgree. Instead, the nasal remains voiced. There is a good markedness reason behind this fact. Due to their relatively open constriction in the supraglottal cavity, the unmarked state of the larynx for sonorants is voicing. This markedness fact is also seen in the cross-linguistic distribution of voicing contrasts in sonorants. Thus, there exist languages with no voicing contrast in the class sonorants. For example, in standard Greek and Arabic all sonorants are voiced. There are also languages with contrastive voiced and voiceless sonorants. Burmese, a Southeast Asian language, for example, has a voiceless series of nasals and lateral approximants along with the voiced series (Ladefoged \& Maddieson 1996). However, 
we know of no language which includes only voiceless sonorants in its segmental inventory. Formally, this markedness observation about sonorants is expressed by the constraint Son-VoI, in (34). It is the presence of this constraint in the grammar which enforces the output [fílusmas] (see Itô, Mester, and Padgett 1996 for other applications of this constraint). The specifics of the ranking are shown in tableau (35). Candidate (35a) illustrates the form with the devoiced $/ \mathrm{m} /$, by analogy to the direction of voicing assimilation in the $3 \mathrm{PL}$ [fílustun]. This incurs a violation of SonVor. Voicing the $/ \mathrm{s} /$, as in (35b) [fíluzmas], incurs a violation of BO-IDENT. Comparing these two candidates with the attested [fílusmas], allows us to add two more ranking relations, SonVoi, BO-Ident >> VoiceAgree.

(34) Son-Voi (SV)

Sonorants must be voiced.

(35) 1 1 PL /fílus-mas/: SonVoi, BO-Ident $>>$ VoICeAgree $>>$ Ident $^{\mathrm{CL}}$

\begin{tabular}{|l||c:c|c|c|}
\hline /fílus-mas/ & SV & BO-I & VA & $\mathrm{I}^{\mathrm{CL}}$ \\
\hline \hline a. fílusmas & $\star !$ & & & $*$ \\
\hline b. fíluzmas & & $* !$ & & \\
\hline c. fílusmas & & & $\star$ & \\
\hline
\end{tabular}

As with dialect A, the constraints MAX, DeP must also be ranked higher than ${ }_{\text {IDENT }}{ }^{\mathrm{CL}}$, because feature change rather than deletion or epenthesis is the option taken for resolving the inhomogeneous specification of voicing in /s-d/ clusters. Finally, the location of UNIFORMITY in the constraint hierarchy of dialect B is irrelevant. That is, this constraint can be ranked anywhere with respect to the other constraints, with no change in the resulting surface forms. In (36), we sum up the ranking relations that must be part of the grammar of dialect B.

(36) Grammar for dialect B

SON-Voi, BO-IDENT $>>$ VoICEAgree $>>$ IdENT $^{\text {CL }}$

MAX $>>$ DEP $>>$ IDENT $^{\text {CL }}$

(UNIFORMITY can be ranked anywhere with respect to these constraints.)

We may compare this grammar to that for dialect A in (32). The most conspicuous difference between the two grammars is the position of BO-IDENT in the two hierarchies, bottom-ranked in A versus top-ranked in B. The top-ranked BO-IDENT in dialect $\mathrm{B}$ has two consequences, the uniform realization of the base /fílus/ as [fílus], and the progressive direction of voicing assimilation in the 
3PL /fílus-dun/ $\rightarrow$ [fílustun].

There is one aspect of dialect B's paradigm that our analysis does not account for. This is the variation in the $3 \mathrm{sg}$ [fílust] [fílusit]. There seems to be no phonotactic reason to motivate the presence of /i/ epenthesis in the latter variant. Final /st/ clusters seem to be well-formed in dialect B in both underived and derived environments, see (30). One account is to posit that the 3sg clitic has two allomorphs, with underlying forms / $t$ / and /it/. Given the general resistance of unstressed high vowels to deletion when these carry morphological function, the fact that the high vowel in [filusit] does not delete is consistent with the hypothesis of a $3 \mathrm{sg} / \mathrm{it} /$ allomorph. A possible source of development of this allomorph is through analogical extension from the Turkish possessive affix /im/, discussed in Section 3. We leave this aspect of dialect $\mathrm{B}$ for future research.

Let us now turn to the standard Greek paradigm, [fílozmu, fílosu, fílostu, fílozmas, fílosas, fílostus]. Unlike dialect B's tolerance of inhomogeneous /s-m/ clusters, e.g., 1PL [fílusmas], standard Greek shows voicing of the final base consonant in the 1sG [fílozmu] and 1PL [fílozmas]. This is the same pattern of base-affecting voicing assimilation as that in dialect A. Hence, standard Greek shares with dialect A the part of the grammar that dictates this voicing assimilation, namely, the ranking VoICEAgree $>>$ BO-IDEnt. However, unlike dialect A's characteristic leveling effects, standard Greek shows no transfer of this voicing to any of the other noun forms within the paradigm. Rather, voicing in standard Greek is observed only in the contexts where voicing assimilation is applicable. Intuitively, this fact suggests that standard Greek differs from dialect A with respect to the position of UNIFORMITY in the constraint hierarchy (see 37 for A's). Tableau (38) confirms this by comparing a subset of the attested standard Greek paradigm [fílozmu, fílostu] with some non-attested sets [fílosmu, fílostu] in (38a) and [fílozmu, fíloztu] in (38b). The set in (38a) incurs a violation of VoiceAgree because of the / $\mathrm{sm} /$ cluster in [fílosmu]. The set in (38b) also incurs a violation of VoICEAGREe because of [fíloztu], and two violations of BO-IDENT because both realizations of the base end in $/ z /$. The attested set in (38c) violates BO-IDENT once, because of the change in the voicing specification of $/ \mathrm{s} /$, and also Uniformity because of the distinct realizations of the base as [fílos] and [fíloz]. By comparing (38a, c), we can infer the low ranked status of UNIFormity and specifically that VoICEAgreE >> BO-IDENT, UNIFORMity.

Dialect A: VoiceAgree, Uniformity $>>$ BO-Ident 
(38) Standard Greek: VoiceAgree $>>$ BO-Ident, Uniformity

\begin{tabular}{|l||c|c:c|}
\hline /fílos-mu, tu/ & VA & BO-I & UNIF \\
\hline \hline $\begin{array}{l}\text { a. fílosmu } \\
\text { fílostu }\end{array}$ & $\star !$ & & \\
\hline $\begin{array}{l}\text { b. fílozmu } \\
\text { fíloztu }\end{array}$ & $\star !$ & $\star *$ & \\
\hline $\begin{array}{l}\text { c. fílozmu } \\
\text { fílostu }\end{array}$ & & $*$ & $*$ \\
\hline
\end{tabular}

Moreover, because the inhomogeneous voicing at the $/ \mathrm{s}-\mathrm{m} /$ boundary is repaired by a featural change rather than by deletion or epenthesis, we must also add the ranking Max, Dep >> BO-Ident, Uniformity. These rankings are illustrated in (39) below.

(39) Standard Greek: Max, Dep >> BO-Ident, Uniformity

\begin{tabular}{|l||c:c|c:c|}
\hline /fílos-mu, tu/ & MAx & DeP & BO-I & UNIF \\
\hline \hline $\begin{array}{l}\text { a. fílomu } \\
\text { fílostu }\end{array}$ & $* !$ & & & \\
\hline $\begin{array}{l}\text { b. fílosimu } \\
\text { fílostu }\end{array}$ & & $* !$ & & \\
\hline $\begin{array}{l}\text { c. fílozmu } \\
\text { fílostu }\end{array}$ & & & & $*$ \\
\hline
\end{tabular}

Let us now compare the attested forms [fílozmu, fílostu] with another realization set, [fílozmu, fílozdu]. In this latter set, uniformity in base realization is achieved without violating the top-ranked VoICEAgree by changing the voicing specification of the clitic/tu/. This way of achieving uniform base realization while satisfying VoiceAgree at the same time was observed in the 3PL of dialect B, /fílus-dun/ $\rightarrow$ [fílustun]. Tableau (40) evaluates the performance of these candidate realizations. Candidate (40a) incurs a violation of IDENT ${ }^{\mathrm{CL}}$ due to the change in the clitic, and two violations of BO-IDENT. The actual forms in (40b) incur one violation of BO-IDENT and one violation of Uniformity. The suboptimality of (40a) is obtained either by the ranking IDENT ${ }^{\mathrm{CL}}>>$ UNIFORMITY or by the ranking BO-IDENT >> UNIFORMITY. 
(40) Standard Greek: either IDENT ${ }^{\mathrm{CL}}>>$ UNIFORMITY or BO-IDENT $>>$ UNIFORMITY

\begin{tabular}{|l||cc|c|}
\hline /fílos $-\mathrm{mu}, \mathrm{tu} /$ & $\mathrm{I}^{\mathrm{CL}}$ & BO-I & UNIF \\
\hline \hline $\begin{array}{l}\text { a. fílozmu } \\
\text { fílozdu }\end{array}$ & $*(!)$ & $* \star(!)$ & \\
\hline $\begin{array}{l}\text { b. fílozmu } \\
\text { fílostu }\end{array}$ & $*$ & $*$ \\
\hline
\end{tabular}

In (41), we summarize the inferred rankings for standard Greek. We have seen that standard Greek is like dialect A and unlike dialect B in that it exhibits voicing of the base-final /s/ before the clitics /mu, mas/. The formal expression of this fact in the grammar of standard Greek consists of the ranking VoICEAgree $>>$ BO-Ident. Moreover, the low-ranked status of Uniformity expresses the fact that, unlike dialect A, standard Greek does not show leveling of voicing to other morphosyntantic contexts.

$$
\begin{aligned}
& \text { Grammar for standard Greek } \\
& \text { VoiceAgree, Max , Dep }>>\text { BO-Ident, Uniformity } \\
& \text { IDENT }^{\mathrm{CL}}>>\text { UNIFORMITY Or BO-IDENT }>>\text { UNIFORMITY }
\end{aligned}
$$

\section{Dissecting the paradigm}

Despite the significant body of work on OO-identity constraints between related words (see the references cited in Section 7), surprisingly little discussion has been devoted to the important issue of which surface forms are to be treated as 'related'. Within inflectional paradigms, in particular, the basic notion of identity assumed is that of UNIFORMITY as adopted so far in our analysis (from Kenstowicz 1997, Steriade, to appear). In this section, we address the issue of 'relatedness' within inflectional paradigms by focusing on dialect A's variation in the $3 \mathrm{sg}$ [fíluzit] [fílust]. Our goal is to show that this variation entails certain refinements in the statement of intra-paradigmatic identity or Uniformity. Specifically, the core proposal of this section is that there are distinct identity constraints holding between distinct forms of the paradigm, and that these constraints are projected on the basis of shared morphosyntactic features along the dimensions of Person and Number. 
The variation in the 3sg [fíluzit] [fílust] indicates that the OO-identity forces, so far expressed by the constraint UNIFormity, can be violated. Specifically, [filust] would be the output produced by (a grammar which includes) the ranking BO-IDENT > UNIFORMity, whereas [fíluzit] would be the output produced by the ranking UNIFORMITY $>>$ BO-IDENT. In this way, it appears that one can express the variation in the 3sg by the variable ranking of the two relevant constraints, Uniformity and BO-IDent. Crucially, however, this variation is seen only in the $3 \mathrm{sg}$. For example, the $1 \mathrm{sg}$ is always [fíluzim], never *[fílusim]. The latter form, ${ }^{\star}$ [fílusim], avoids an illicit final /sm/ cluster by epenthesis, as expected, but it does not voice the $/ \mathrm{s} /$, remaining faithful to the base /fílus/. In terms of constraint ranking, the non-attested ${ }^{\star}$ [fílusim] in dialect A implies that the leveling forces of UNIFORMITY are invariably ranked higher than BO-Ident. Hence, the presence of variation in the $3 \mathrm{sg}$ forces one to conclude that UNIFORMITY can sometimes be ranked below BO-IDENT, but the absence of variation in the $1 \mathrm{sg}$ indicates that UNIFORMITY is always ranked above BO-IDENT.

We have arrived at a contradiction. If the identity requirements between the $1 \mathrm{SG}$ [filuzim] and the 1PL [filuzmas], on the one hand, and that between the 1sG [fíluzim] and the 3sg [fíluzit] [fílust], on the other hand, are enforced by the same constraint, a single UNIFORMITY, we do not predict the state of affairs that is true of dialect A. Rather, a single Uniformity constraint predicts either no variation in 1sG and 3sg (i.e., [fíluzim] along with [fíluzit] or [fílusim] along with [fílusit]) or variation in both 1sG and 3sg (i.e., [fílusim] [fíluzim] along with [fílust] [fíluzit]).

This contradiction is resolved by positing distinct identity relations and thus distinct identity requirements holding within the paradigm. One identity constraint holds between the 1sG and the 1PL. These two forms share the morphosyntactic feature [+first person] along the Person dimension. We thus call this type of identity constraint 'Person identity'. Person identity is to be contrasted with the identity requirement between the 1 sG and the 3sG. These two forms share the morphosyntactic feature [+singular] along the Number dimension, and we call their identity constraint 'Number identity'. Schematically, the network of these morphosyntactically-driven identity relations is depicted in (42). The horizontal boxes indicate that a Person identity constraint holds between the two enclosed forms, and the elipses indicate that a Number identity constraint holds between the enclosed forms. 
(42) Distinct identity relations along the categories of Person and Number

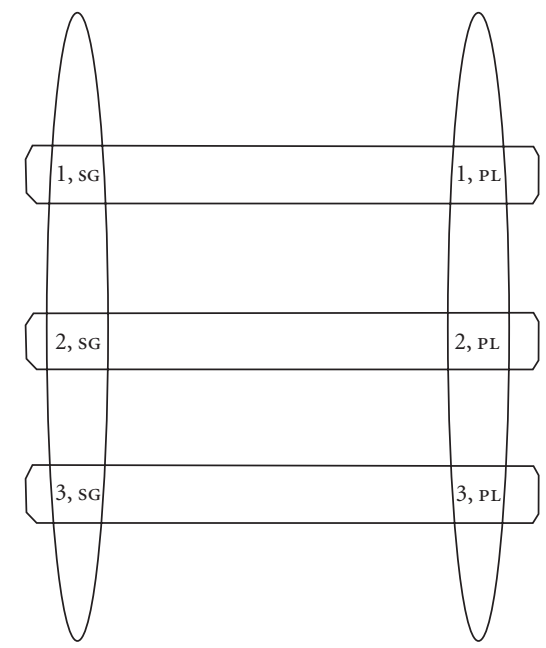

Since distinct identity requirements are involved, they project distinct constraints in the grammar. Since the constraints are distinct, they may have different 'strengths' or they may reside at different places in the constraint ranking. Therefore, it is now possible to account for the state of affairs present in dialect $\mathrm{A}$, namely, the cooccurrence of absence of variation in the $1 \mathrm{sG}$ [fíluzim] and presence of variation in the 3sg [fíluzit] [fílust]. Intuitively, the identity constraint between the 1sG [fíluzim] and 1PL [fíluzmas] is never violated, but the (now distinct) identity constraint between the 1sG [fíluzim] and the 3sG [fíluzit] [fílust] is violated when the 3sg surfaces as [fílust].

We now turn to express in formally explicit terms the role of distinct Person and Number identity constraints in the grammar. Following our proposal, the UNIFORMITY constraint is replaced by OO-identity constraints which are projected along the morphosyntactic dimensions of the paradigm, here, Person and Number. These constraints demand identity between output forms sharing some morphosyntactic feature along one of these dimensions. Thus, we call the OO-identity constraint that holds between the 1sG and the 1PL, OO-IDENT $[+1 \mathrm{st}]$, and that holding between the $1 \mathrm{sg}$ and $3 \mathrm{sg}$, OO-IDEnt $[+\mathrm{Sg}]$.

Tableau (43) addresses the 1sG. The input to the 1sg is /fílus-mu/. The output is [fíluzim] (henceforth, in tableaux we write OO-I for OO-IDENT). BO-IDENT is violated because of the change between base /s/ and output /z/. The reason why BO-IDENT is violated as we go from /fílus-mu/ to [fíluzim] is 
because of the OO-IDENT constraint between the 1sG and the 1PL. Hence, as shown in (43), we can infer that OO-IDEnt [+1st] >> BO-IDENT. Intuitively, the Person identity requirement between the $1 \mathrm{SG}$ and the $1 \mathrm{PL}$ is stronger than the BO-identity requirement between the base /fílus/ and its output form. This tableau is essentially the same as that in (28); we have replaced UNIFORMITY with the specific constraint holding between the 1sG and the 1PL.

(43) Ranking for 1sg [fíluzim], 1PL [fíluzmas]: OO-IDENT[+1st] >> BO-IDENT

\begin{tabular}{|l||c|c|}
\hline$/$ /fílus-m/ & OO-I[+1st $]$ & BO-I \\
\hline \hline a. fílusim & $\star !$ & \\
\hline b. fíluzim & & $*$ \\
\hline
\end{tabular}

Consider now the 3sg in (44) below. The input to the 3sg is /fílus-tu/ and the output varies between [filust] and [fíluzit]. When the output is [fílust], BOidentity to /fílus/ wins over OO-identity to the 1sg [fíluzim]. Hence, output [fílust] implies that BO-IDENT $>>$ OO-IDENT[+Sg]. In addition, BO-IDENT must be ranked higher than the constraint demanding a voiced $/ \mathrm{z} /$ in the $3 \mathrm{sg}$ because there is a $/ \mathrm{z} /$ in the $3 \mathrm{PL}$. This is the constraint OO-IDENT[+3rd]. This ranking is shown in the next tableau.

(44) Identity suppression between 3sg [fílust] and 1sG [fíluzim], 3PL [fíluzdun]

\begin{tabular}{|l||c|c:c|}
\hline$/$ fílus-t/ & BO-I & OO-I $[+\mathrm{Sg}]$ & OO-I $[+3 \mathrm{rd}]$ \\
\hline \hline a. fíluzit & $* !$ & & \\
\hline c. fílust & & $*$ & $*$ \\
\hline
\end{tabular}

In (45), we summarize the constraint hierarchy that accounts for the paradigm with the differential uniformity effects, that is, the forms 1sg [fíluzim], with leveling of voicing, and 3sg [fílust], with no leveling.

(45) Grammar for 1sg [fíluzim], 3sg [fílust] OO-IDENT [+1st] >> BO-IDENT > OO-IDENT [+Sg], OO-IDENT[+3rd]

When the 3sG is [filuzit], then one or both of the lowest-ranked constraints above are promoted higher than the BO-IDENT constraint. That is, as shown in (46), Person identity between the 3sG and 3PL, or Number identity between the 
$3 \mathrm{sG}$ and the 1sG, or both constraints, are promoted to the top of the constraint hierarchy, just like the Person identity constraint between the 1sG and the 1PL.

(46) Grammars for 1sg [fíluzim] and 3sg [fíluzit]

OO-IDEnt [+1st], OO-IDENT[+3rd] >> BO-IDENT $>>$ OO-IDENT[+Sg]; or

OO-IDENT [+1st], OO-IDENT [+Sg] $>>$ BO-IDENT $>>$ OO-IDENT[+3rd]; or

OO-IDEnt $[+1 s t]$, OO-IDEnt $[+\mathrm{Sg}]$, OO-IDEnt $[+3 \mathrm{rd}]>>$ BO-IDENT

To sum up, dialect A shows variation in the presence of voicing in the 3sG [fíluzit] [fílust], but no variation in the 1sG [fíluzim] (that is, no *[fílusim]). We have shown that a single UNIFORMITY constraint is incompatible with this state of affairs, as it predicts uniform presence or absence of variation across all forms in the paradigm. This argues that, within a paradigm, OO-identity constraints solicit identity between forms of a particular person (e.g., first or third) or a particular number (e.g., singular or plural), only. Specifically, Person identity between the 1sG and the 1PL is never violated, as shown by the pair [fíluzim], [fíluzmas] (no variation). But Number identity between the 3sg and the $1 \mathrm{sG}$, and Person identity between the $3 \mathrm{sg}$ and the $3 \mathrm{PL}$ can be violated. For Number identity, this is shown by the pair 3sg [fílust], 1sG [fíluzim], and for Person identity by the pair 3sG [fílust], 3PL [fíluzdun]. Such variation within the same dialect is expressed in formal terms by the variable ranking between the constraint demanding identity to the base form BO-IDENT and the intraparadigmatic identity constraints OO-IDENT [+Sg], OO-IDENT[+3rd], holding between the 1sG, 3sG and between the 3sG, 3PL, respectively.

\section{Conclusion}

This paper is concerned with the role of the morphological paradigm in shaping the phonological properties of the [noun-clitic] cluster within two dialectal varieties of the island of Lesvos. We have seen that to account for certain aspects of the phonological realization of the various [noun-clitic] forms, the grammar must crucially include constraints that require identity among the surface forms of the paradigm. We have formalized such constraints in terms of OutputOutput correspondence relations, building in this way on other studies of intraparadigmatic relations in the literature. The interaction of such constraints with other independently necessary properties of the phonology and morphology of the two dialectal varieties of Lesvos derives some realization properties of 
[noun-clitic] combinations which would otherwise seem puzzling. We have made two specific proposals about the precise statement of intra-paradigmatic identity in the grammar. First, identity constraints must have a limited domain of application, circumscribed by the forms of the paradigm and only those. Second, we have presented evidence that intra-paradigmatic identity constraints hold along the morphosyntactic dimensions of Person and Number, which enter into the construction of the paradigm. The statement of intra-paradigmatic identity is expressed through constraints which require identity between two forms sharing a morphosyntactic feature such as [+singular] or [+third person], along the dimensions of the paradigm.

\section{Notes}

* A first version of this paper was presented at the First Greek Dialects and Linguistic Theory Conference (Patras, October 2000). We thank the audience and especially M. Margariti-Roga for insightful remarks. We are very grateful to an anonymous reviewer whose most constructive comments have improved this paper considerably. The authors' names appear in alphabetical order.

1. On the statement of the OCP and its dependence on the featural make-up of segments see Mester (1986), McCarthy (1988), Yip (1989, Padgett (1992), and Gafos (in press).

2. We thank an anonymous reviewer for pointing out to us the distinction between firstcoronal deletion in standard Greek and /s/-deletion in Lesvian.

3. An anonymous reviewer suggests that the hypothesis of a Turkish influence for /i/ epenthesis is weakened by the fact that the same phenomenon has been reported in northern Greek dialects of areas that do not border with Turkey (see Newton 1972). Thus, in Epeiros we find /pónos-mu/ 'my pain' $\rightarrow$ [pónusim], and in Thessaly / $\delta$ ikós-mu/ 'my own' $\rightarrow$ [Өkózum]. However, it is true that even those areas have been under a Turkish occupation for more than four centuries.

4. In this context, / ¿én/ is realized as [én].

5. The issue of whether the [host-clitic] group behaves as a phonological/prosodic word, and whether phrasal affixes have the same characteristics as other affixes require further research which falls beyond the scope of this paper.

6. It should be noticed that the Lesvian epenthetic/i/ cannot derive from the well-known standard Greek verbal augment /e-/, which appears in unstressed position in the past tense, e.g., [épina] 'I was drinking', [píno] 'I drink'. As noted earlier, mid-vowel raising takes place in unstressed position, whereas the /e-/ of the augment is in a stressed position. Moreover, the Lesvian epenthetic /i/ appears in both present, see (12b,c), and past tense forms as in [én

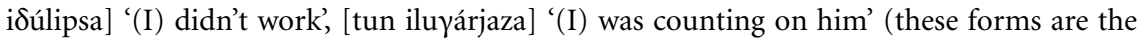

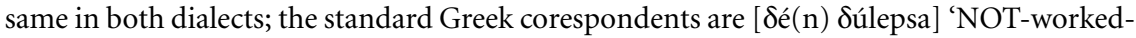
PERF-PAST-1SG', [ton eloyárjaza] 'HIM-counted-IMPERF-PAST-1SG'. On the contrary, an 
augment is expected only in the environment of the past tense. Note also that the Lesvian past verbal forms with more than two syllables, e.g., [luyarjázu] (standard Greek [luyarjázo]) 'count' do not generally take an augment, [luyárjaza] 'I was counting', when they are not preceded by a proclitic or a particle. See Babiniotis (1972) and Ralli (1988) for an analysis of the Greek augment as a stress carrier.

7. The problems that are encountered in an attempt to explain the voicing and the vowel epenthesis in the 1sG of [noun-clitic] forms of the northern Greek dialects of Zagori, Velvendos and Thasos, by using rule-ordering along the lines of Newton (1972), are also discussed in a paper by Malikouti-Drachman \& Drachman (1977:47-49).

8. To fully establish our claim, note that we cannot say that the 3sg [fíluzit] is derived from the 1sG [fíluzim] or the 1PL [fíluzmas] thereby inheriting the voicing of these latter forms (e.g., /fíluzim $+\mathrm{t} / \rightarrow \ldots$ [fíluzit]). Such a derivation would necessitate an otherwise completely unsupported rule of truncation of the $1 \mathrm{sG}$ or $1 \mathrm{PL}$ marker, $/ \mathrm{m}$, mas/, before the $3 \mathrm{sG}$ marker /t/. It also follows from this that it is not possible to explain the voicing in the 3s by the mechanism of the cycle (see Chomsky \& Halle 1968, Kenstowicz 1994).

9. We assume that VoiceAgree requires homogeneity in voicing for both [fíluzmas] and [fíluzdun]. However, the two consonant clusters differ in that the first consists of an obstruent-sonorant and the other of an obstruent-obstruent sequence. These may be subject to different voicing requirements. Though we are aware that it may not be accurate to adopt the same constraint across the different types of clusters, we do assume a single VoiceAgree for present purposes. This assumption does not compromise the validity of the ensuing results.

10. In Greek, Philippaki-Warburton (1976) has discussed the important role of uniformity in the development of the inflectional paradigms.

11. For the notion of adjacency in phonological assimilations see Arachangeli \& Pulleyblank (1994), Gafos (1996 [1999]) and Ní Chiosáin \& Padgett (to appear).

12. Another candidate that satisfies both VoiceAgree and Uniformity is [fílusim, fílusmas, with a voiceless $/ \mathrm{m} /$ in the $1 \mathrm{PL}$. This latter form, however, violates the constraint against voiceless sonorants, Son-VoI, which is introduced later, and the faithfulness constraint for clitics, IDENT ${ }^{\mathrm{CL}}$, which was shown to be ranked higher than BO-IDENT.

13. As suggested by an anonymous reviewer, an alternative hypothesis for the suboptimality of [fíluzd] is to invoke a constraint that disallows word-final /zd/ clusters. However, because of the rarity of /d/-final words we are not able to test the validity of this hypothesized aversion to /zd/ clusters. We thus chose to exclude this candidate using resources that are needed independently in our analysis.

\section{References}

Anderson, Stephen. 1992. A-morphous Morphology. Cambridge: Cambridge University Press. Anttila, Raul. 1977. Analogy. The Hague: Mouton. 
Archangeli, Diane and Douglas Pulleyblank. 1994. Grounded Phonology. Cambridge, Mass.: MIT Press.

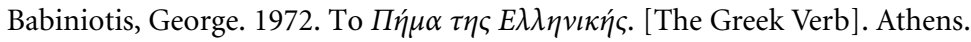

Benua, Laura. 1995. 'Identity Effects in Morphological Truncation'. In Jill Beckman, Suzanne Urbanczyk, and Laura Walsh (eds.), University of Massachusetts Occasional Papers in Linguistics 18: Papers in Optimality Theory, GLSA, Amherst: University of Massachusetts, pp. 77-136.

Buckley, Eugene. 1999. 'Uniformity in Extended Paradigms'. In The Derivational Residue in Phonological Theory, Ben Hermans and Marc van Oostendorp (eds.), pp. 81-104, Benjamins.

Burzio, Luigi. 1993. 'English Stress, Vowel Length and Modularity’. Journal of Linguistics 29, pp. 359-418.

Burzio, Luigi. 1994. Principles of English Stress. Cambridge: Cambridge University Press.

Burzio, Luigi. 1998. 'Multiple Correspondence'. Lingua 104, pp. 79-109.

Chomsky, Noam and Morris Halle. 1968. The Sound Pattern of English. Harper and Row, New York.

Drachman, Gaberell and Angeliki Malikouti-Drachman. 1999. 'Greek Word Accent'. In Harry van der Hulst (ed.), Word Prosodic Systems in the Languages of Europe, pp. 897-945, Mouton De Gruyter: Berlin \& New York.

Fromkin, Victoria A. (ed.). 2000. Linguistics: An Introduction to Linguistic Theory. Oxford: Blackwell.

Gafos, Adamantios. 1996. The Articulatory Basis of Locality on Phonology. Ph.D. dissertation, Johns Hopkins University. [Published 1999, New York: Garland Publishers.]

Gafos, Adamantios. In press. 'A Grammar of Gestural Coordination'. Natural Language and Linguistic Theory 20.

Itô, Junko, Armin Mester and Jaye Padgett. 1996. 'Licensing and Underspecification in Optimality Theory'. Linguistic Inquiry 26, pp. 571-613.

Kenstowicz, Michael. 1994. Phonology in Generative Grammar. Oxford: Blackwell.

Kenstowicz, Michael. 1997. 'Base Identity and Uniform Exponence: Alternatives to Cyclicity'. In Current Trends in Phonology: Models and Methods, Jacques Durand and Bernard Laks (eds.), pp. 363-393. Salford, Manchester: European Studies Research Institute.

Kiparsky, Paul. 1982. 'Analogical Change as a Problem for Linguistic Theory'. In Paul Kiparsky (eds.) Explanation in Phonology. Dordrecht: Foris, pp. 217-36.

Kiparsky, Paul. 1995. 'The Phonological Basis of Sound Change'. In John Goldsmith (eds.) Handbook of Phonological Theory, pp. 640-670. London: Basil Blackwell.

Kraska-Szlenk, Iwona. 1995. The Phonology of Stress in Polish. Ph.D. dissertation, University of Illinois, Urbana-Champaign.

Kretschmer, Paul 1905. Neugriechische Dialektstudien I, Der Heutige Lesbische Dialekt. Wien: Alfred Hoelder.

Ladefoged, Peter and Ian Maddieson. 1996. The Sounds of the World's Languages. Blackwell: Oxford.

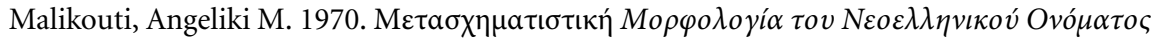
[Transformational Morphology of the Modern Greek Noun]. Ph.D Dissertation, University of Athens. 
Malikouti-Drachman, Angeliki and Gaberell Drachman 1977. 'Túroı $Ф \omega v o \lambda o \gamma \iota \kappa \omega ́ v ~ N o ́ \mu \omega v$

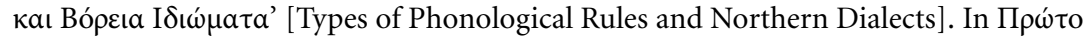

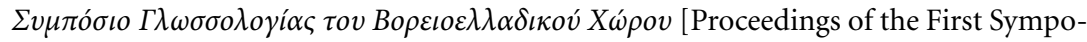
sium of Northern Greece]. Thessaloniki, pp. 37-50.

McCarthy, John J. 1979. Formal Problems in Semitic Phonology and Morphology. Ph.D. dissertation, MIT, Cambridge, MA. [Published 1985, New York: Garland Publishers.]

McCarthy, John J. 1986. 'OCP Effects: Gemination and Antigemination'. Linguistic Inquiry 17, pp. 207-263.

McCarthy, John J. 1988. 'Feature Geometry and Dependency: a Review'. Phonetica 45, pp. 84-108.

McCarthy, John J. 2000a. 'Faithfulness and Prosodic Circumscription'. In Joost Dekkers, Frank van der Leeuw, \& Jeroen van de Weijer, (eds.), The Pointing Finger: Conceptual Studies in Optimality Theory, pp. 151-189. Amsterdam: HIL.

McCarthy, John J. 2000b. 'The Prosody of Phase in Rotuman'. Natural Language and Linguistic Theory, pp. 147-197.

McCarthy, John J. and Alan Prince. 1993.'Prosodic Morphology I: Constraint Interaction and Satisfaction'. Technical Report \#3, Rutgers University Center for Cognitive Science, pp. 184.

McCarthy, John J. and Alan Prince. 1995. 'Faithfulness and Reduplicative Identity'. In Jill Beckman, Suzanne Urbanczyk, and Laura Walsh (eds.), University of Massachusetts Occasional Papers in Linguistics 18: Papers in Optimality Theory, GLSA. Amherst: University of Massachusetts, pp. 249-384.

Mester, Armin. 1986. Studies in Tier Structure. Ph.D. dissertation, University of Massachussets, Amherst. [Published 1988, New York: Garland Publishers.]

Newton, Brian. 1972. The Generative Interpretation of Dialect: A Study of Modern Greek Phonology. Cambridge Studies in Linguistics 8. New York and London: Cambridge University Press.

Ní Chiosáin, Maire and Jaye Padgett. To appear. 'Markedness, segment realization, and locality in spreading'. In Linda Lombardi (ed.), Constraints and representations: segmental phonology in Optimality Theory. New York and London: Cambridge University Press.

Padgett, Jaye. 1992. 'OCP Subsidiary Features'. In Proceedings of NELS 22, GLSA, Department of Linguistics, University of Massachusetts, Amherst, Mass., pp. 335-346.

Philippaki-Warburton, Irene 1976. 'On the Boundaries of Morphology and Phonology: A Case Study from Modern Greek'. Journal of Linguistics 12, pp. 259-278.

Prince, Alan and Paul Smolensky. 1993. Optimality Theory: Constraint Interaction in Generative Grammar. Ms., Rutgers University, New Brunswick, N. J., and University of Colorado, Boulder.

Ralli, Angela 1988. Elements de la Morphologie du Grec Moderne: La Structure du Verbe. Ph.D. Dissertation. University of Montreal.

Steriade, Donca. To appear. 'Paradigm Uniformity and the Phonetics-Phonology Boundary'. In Janet Pierrehumbert and Michael Broe (eds.), Papers in Laboratory Phonology Vol. 6. New York and London: Cambridge University Press.

Yip, Moira. 1989. 'Feature Geometry and Cooccurrence Restrictions'. Phonology 6, pp. 349-374. 


\section{$\Pi \varepsilon \rho \dot{\lambda} \lambda \eta \psi \eta$}

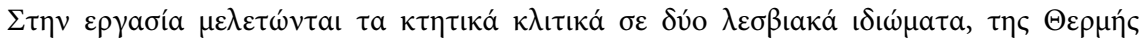

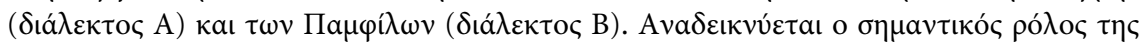

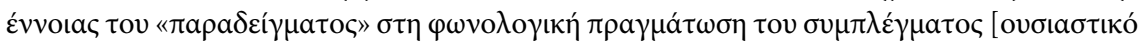

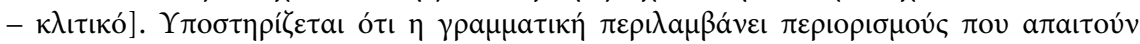

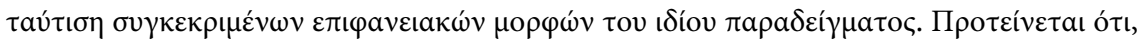

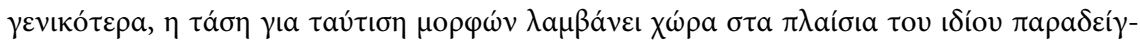

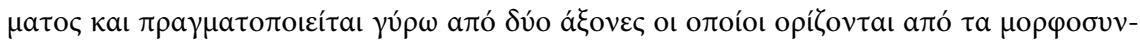

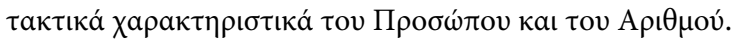

